\title{
Student Perceptions of College Teacher Misbehaviors and Teacher Credibility as Perceived by Jordanian University Students
}

\author{
Zohair H. Al-Zoubi \\ Department of Foundations and Administration, Faculty of Education Sciences, The Hashemite University, Zarqa, Jordan
}

\author{
Doi:10.5901/mjss.2016.v7n2p324
}

\begin{abstract}
This study aimed to identify levels of teacher misbehavior and teacher credibility among a group of undergraduate students in Jordan, and investigate the relationship between them. Data were collected from a questionnaire in the fields of teacher misbehavior and teacher credibility were administered to a study sample of 273 male and female undergraduate students at the Hashemite University during the academic year 2015/2016. Results indicated that the student perception of both teacher misbehavior and teacher credibility was medium level. Moreover, results showed a negative and statistically significant relationship between irresponsibility and teacher credibility. Upon the findings of the current study, many recommendations were made to examine the psychometric qualities of the multidimensional perfectionism scale and motivation orientation scale in other populations such as secondary school students.
\end{abstract}

Keywords: College teacher misbehavior, Teacher credibility, Jordanian university student.

\section{Introduction}

Assessments of the various facets of teacher effectiveness are in the main based on student opinion surveys and according to a report by McMillan and Cheney in (1996), students are rarely satisfied with their classroom experiences and instructors. A study by Pozo-Munoz, Rebolloso-Pacheco, and Fernandez-Ramirez (2000) is also critical of this methodology, commenting that although useful, such student evaluations are often subjective and potentially biased, influenced by the teacher's appearance, personality and attitude. Hattie (2009) supported this statement, adding that since methods of determining teacher quality continued to rely predominantly on student assessments, the whole process of teacher evaluation needs to be examined and understood, bearing in mind the strong association between student achievement and the quality of the teacher-student relationship.

\section{Teacher Misbehavior}

Although there has been no lack of research conducted on the attributes of "good" teachers, there is considerably less available on what is perceived to constitute "bad" teachers.

Kearney, Plax, Hays, \& Ivey (1991) were the first to conduct a communication study, the focus of which was identification of teacher behavior which students disliked or found objectionable, and thus engendered the concept of teacher misbehavior.

Kearny, Plax, Sorensen, \& Smith (1988) made the point that the focus of instructional research has hitherto been confined to means of reducing student misbehavior in the classroom, whereas Kearny, Plax, \& Allen, 2002 observed that misbehavior in education settings is not solely confined to students, but that teachers also can and do misbehave in the classroom.

Kearney et al (1991) state a definition of teacher misbehaviors any behavior displayed by the teacher which has a negative impact on instruction or impedes student learning. Kearney et al (1991) elaborate further, identifying three distinct yet related lines of research into teacher misbehavior: the first, as identified by Kelsey, Kearney, Plax, Allen, \& Ritter, (2004); McPherson \& Young (2004), involves relevant theoretical frameworks such as attribution theory, while in their study, Berkos, Allen, Kearney \& Plax (2001) include the norm violation model.

The focus of the second line of research is the variables affecting student perception of teacher misbehavior, Thweatt \& McCrosky $(1996,1998)$ using the terms 'teacher immediacy and non-immediacy', while Wanzer \& McCrosky (1998) mention teachers' socio-communicative styles.

The third line focuses on the detrimental effects of teacher misbehavior on both student and teacher incurring, 
according to Kearney et al (1991); McPherson, Kearny \& Plax, (2006) adverse and negative consequences to the learning process, student motivation(Christophel \& Gorham, 1995; Gorham \& Christophel, 1992; Gorham \& Milleette, 1997; Zhang, 2007), satisfaction with the effectiveness of the course and the instructor (Banfield, Richmond \& McCroskey, 2006; McPherson, Kearny \& Plax, 2006; Myers, 2002), student perceptions of teacher credibility(Banfield et al, 2006), affective learning (Banfield et al, 2006; Dolin, 1995; Toale, 2001),teaching evaluations (Schrodt, 2003; Wanzer \& McCrosky, 1998), and cognitive learning (Dolin, 1995; Myers, 2002).

Kearney et al (1991) defined teacher misbehavior as any communication behavior that impedes or distracts student from learning. On the basis of students' reports they identified 28 dimensions of teacher misbehavior which were ultimately reduced to the following three: offensiveness, indolence, and incompetence.

Teacher offensiveness is associated with the characterization of teachers as mean, cruel, and ugly. There are six categories of misbehavior including displays of favoritism, the use of putdowns and sarcasm, and relying on unreasonable or arbitrary rules. Offensive teachers habitually resort to a demeaning manner toward students by being condescending and self-centered, humiliating students by ridiculing them, their work and their ideas.

Teacher incompetence is typified by indifference to the students or the course, and defined as a group of behaviors that imply the teacher's disinterest in the students and/or the course which he/she is responsible for teaching. There are nine categories which include unfair testing, poorly planned, prepared or boring lectures, and information overload.

Incompetent teachers typically exhibit lack of motivation and enthusiasm, in addition to ignorance and confusion in regard to the course content.

According to Kearney et al (1991);Kearney et al (2002), and McPherson et al (2006) teacher indolence is graphically characterized by the stereotyped absentminded professor. The six categories of indolence include: frequently being absent or tardy, being disorganized and unprepared, and information 'under load' - giving students inadequate information. Examples of teacher indolence include forgetting assignments or test dates, failing to grade assignments in a timely manner, and failing to show up for lectures.

Zhang (2007) noted that although the most common misbehavior reported in the literature is teacher incompetence, Dolin (1995) and Toale, (2001) note that it has been proven overwhelmingly that student learning outcomes may be significantly jeopardized by any form of teacher misbehavior. In addition, Kelsey, Kearney, Plax, Allen, \& Ritter (2004) reiterate that student performance may also be significantly influenced by the students' perceptions of teachers.

\section{Teacher Credibility}

As a result of their studies into understanding the communication process, McCroskey, Holdridge \& Toomb (1974); Teven \& McCrosky (1996) and Teven \& Hanson (2004), state that 'teacher ethos' or the more commonly used contemporary term "source credibility" is fundamentally significant for both teachers and learners. It has been noted however that teacher credibility has been associated with verbal aggression Myers, (2001); Schrodt (2003), sexual orientation Russ, Simonds, \& Hunt (2002), and immediacy, identified by Thweatt \& McCroskey (1998) and Teven \& Hanson (2004).

McCroskey \& Young (1981) and McCroskey \& Teven (1999) define teacher credibility as the attitude of a student toward a teacher's perceived believability, whereas instructor credibility as defined by McCroskey \& Young (1981, p.24), is "the attitude toward a source of communication held at a given time by a communicator."

McCroskey, Valencic \& Richmond (2004)and Myers \& Martin (2006) identified teacher credibility as a critical teacher attribute in the instructional process and one of the most significant variables affecting teacher-student interaction and relationships. These findings, with the addition of student motivation and learning, were supported by Teven \& McCroskey (1997), Pogue \& AhYun (2006), Johnson \& Miller (2002), and Teven (2007).

McCroskey \& Young (1981), defined three dimensions of instructor credibility: competence, character, and caring, illustrating competent instructors as those who demonstrated a thorough knowledge of the subject matter and were consequently perceived to be intelligent and qualified to teach their subject.

Frymier \& Thompson (1992); Thweatt \& McCroskey (1998) found that those instructors deemed to be responsible, honorable and trust worthy were also considered to be sincere, selfless, and respectable, while Teven \& McCroskey (1996) found that such caring instructors were considered to be student centered, concerned about their welfare and responsive to students' problems. Taking into account variance in levels of perceived competence, character, and caring, those instructors considered the most credible scored highly on these three dimensions. 


\section{The Current Study}

There is very little research, and less systematic research in Jordan as well as in the Arab world, which attempts to identify the kind of behavior that teachers may manifest to damage that relationship. Such behavior has recently been characterized as teacher misbehavior (Lewis \& Riley, 2009). To data, examinations of the effect of teacher misbehavior on students perceptions of students perception of teacher credibility is limited in Jordan college classroom. More specifically, the objectives of the current study were to:

1. To determine the perceptions of students toward teacher misbehavior and teacher credibility.

2. To investigate the relationship between teacher misbehavior and teacher credibility.

\section{Methodology}

\subsection{Participants}

The present sample was 273 undergraduate students selected from among students enrolled in standard curriculum courses at the Hashemite University in Jordan, in the second semester of the academic year 2015-2016. The sample was comprised of 39 males(13\%) and 234 females (87\%). The mean age of participants was 20.4 years (SD=3.30).

\subsection{Instruments}

The Taiwanese Teacher Misbehavior Scale (TTMS): the TTMS was developed by Hsu (2013). The scale consists of 28 items, which must be answered on the basis of a 5-point Lickert scale, ranging from the response (1) never, to (5) very often. The items represent four scales: derisiveness(ten items, e.g., When the teacher talks about a student he/she doesn't like, he/she is critical, picky or cold), incompetence(nine items, e.g., The teacher doesn't organize or plan for his/her teaching), irresponsibility (five items, e.g., The teacher dozes off during students report or when monitoring exams), and non-immediacy(four items, e.g., The teacher never changes teaching methods. The class is boring, always the same, and not attractive).

The authors who designed the instrument reported that the reliability of the scales included in the TTMS ranged from adequate to very good, the alpha reliability for TTMS was 0.97 .

The Cronbach alpha for the current study was $.90, .87, .79$, and .79 respectively for derisiveness, incompetence, irresponsibility, and non-immediacy.

\subsection{Teacher Credibility Scale}

Developed by McCroskey \& Teven (1999) this scale consists of 18 seven-point bipolar descriptions(e.g., intelligent/unintelligent and trustworthy/ untrustworthy) designed to illustrate the three dimensions of perceived source credibility: competence, caring, and trustworthiness. In studies undertaken by McCroskey \& Teven (1999) and Myers \& Martin (2006), the reliability of previous studies was accepted.

In the current study, the Cronbach alpha results were $0.74,0.75$, and 0.69 respectively for the three dimensions of competence, caring, and trustworthiness.

\subsection{Procedures}

In order to ensure conceptual and linguistic equivalence between the original English language scale and an Arabic version, it was translated into Arabic then back-translated into English by different bilingual scholars. The purpose of the study, requirements, anonymity and privacy assurances were explained immediately preceding the start of the class; participants were then asked to complete the questionnaire which would require approximately 25 minutes.

\subsection{Data analysis}

In order to determine the relationship between teacher misbehavior and students' perception of teacher credibility, participants' responses to the research objective were analyzed using one-way ANOVA (Analysis of Variance), means, standard deviations, and multiple correlations. SPSS version 17 (Statistical Package for Social Sciences) was used to analyze the data, with a statistical significance level of 0.05 . 


\section{Results}

The study objective was to determine the perceptions of students regarding teachers' misbehaviors and teacher credibility, among students at the Hashemite University in Jordan, using descriptive statistics, means and standard deviation to achieve this objective. The students' perceptions levels were interpreted using the following categories: below 3= low, 3-4= medium, and above 4= high perception level.

Table 1 shows that the most frequent perception of teacher misbehavior was found to be irresponsibility $(M=3.65$, $S D=0.91)$, followed by incompetence $(M=3.23, S D=0.74)$, and derisiveness $(M=3.15, S D=0.85)$ and then non-immediacy $(M=3.04, S D=0.89)$. The mean for overall reading strategies use was $(M=3.89, S D=0.43)$. Table 1 also showed that the most frequent of the students perceptions of teacher credibility was found to be trustworthiness $(M=3.77, S D=0.99)$, followed by caring $(M=3.73, S D=0.97)$ and then competence $(M=3.45, S D=0.97)$. These results reveal that the students' perceptions of teacher misbehavior and teacher credibility were rated at a medium level.

Table 1: Means (M), and Standard Deviations (SD) for teacher misbehavior and teacher credibility

\begin{tabular}{|c|c|c|}
\hline Variable & $\mathrm{M}$ & SD \\
\hline \multicolumn{3}{|c|}{ Teacher misbehavior } \\
\hline Derisiveness & 3.15 & 0.85 \\
\hline Incompetence & 3.23 & 0.74 \\
\hline Irresponsibility & 3.65 & 0.91 \\
\hline Non-immediacy & 3.04 & 0.89 \\
\hline \multicolumn{3}{|c|}{ Teacher credibility } \\
\hline Competence & 3.45 & 0.97 \\
\hline Caring & 3.73 & 0.97 \\
\hline Trustworthiness & 3.77 & 0.99 \\
\hline
\end{tabular}

The aim of study objective two was to investigate the relationship between teacher misbehavior and student perceptions of teacher credibility. The Pearson correlation coefficient $(r)$ was used to achieve this objective. Table 2 shows that irresponsibility was significantly and negatively associated with teacher credibility, while no significant correlations were found between derisiveness, incompetence and non-immediacy types of teacher misbehavior and teacher credibility.

Table 2: Correlation between teacher misbehavior and teacher credibility

\begin{tabular}{|l|c|c|c|c|c|c|c|c|}
\hline Variables & $\mathbf{1}$ & $\mathbf{2}$ & $\mathbf{3}$ & $\mathbf{4}$ & $\mathbf{5}$ & $\mathbf{6}$ & $\mathbf{7}$ & $\mathbf{8}$ \\
\hline 1.Derisiveness & 1 & & & & & & & \\
\hline 2.Incompetence & $0.78^{\star}$ & 1 & & & & & & \\
\hline 3.Irresponsibility & $0.60^{\star}$ & $0.72^{\star}$ & 1 & & & & & \\
\hline 4.Non-immediacy & $0.64^{\star}$ & $0.71^{\star}$ & $0.55^{\star}$ & 1 & & & & \\
\hline 5.Competence & -0.10 & -0.04 & -.0 .05 & 0.06 & 1 & & & \\
\hline 6.Caring & -0.11 & -.009 & $-0.12^{\star \star}$ & $-0.20^{*}$ & $0.36^{\star}$ & 1 & & \\
\hline 7.Trustworthiness & -0.13 & -0.03 & -0.09 & -0.09 & $0.20^{\star}$ & $0.21^{*}$ & 1 & \\
\hline 8.Teacher credibility & -0.04 & -0.05 & $-0.13^{*}$ & -0.09 & $0.66^{\star}$ & $0.20^{*}$ & $0.21^{*}$ & 1 \\
\hline
\end{tabular}

An independent sample one-way analysis of variance (ANOVA) was computed to examine the effect of the independent variables (Derisiveness, Incompetence, Irresponsibility, and Non-immediacy) on the dependent variable(students' perceptions of teacher credibility). The results of ANOVA analysis revealed statically significant differences as: derisiveness $(F=4.950, P=0.00)$, incompetence $(F=7.298, p=0.00)$, irresponsibility $(F=5.545, p=0.00)$, and nonimmediacy $(F=6.916, p=0.00)$. Table 3 displayed the summary.

Table 3: Summary of ANOVA for four types of teachers' misbehavior impact on students' perception of teachers' credibility

\begin{tabular}{|l|l|c|c|c|c|c|}
\hline Variables & Source & SS & df & MS & F & $p$ \\
\hline \multirow{2}{*}{ Derisiveness } & Between & 90.351 & 40 & 2.259 & \multirow{2}{*}{4.950} & \multirow{2}{*}{$0.00^{*}$} \\
\cline { 2 - 5 } & Within & 105.870 & 232 & 0.456 & & \\
\hline
\end{tabular}




\begin{tabular}{|c|c|c|c|c|c|c|}
\hline & Total & 196.220 & 272 & & & \\
\hline \multirow[t]{3}{*}{ Incompetence } & Between & 83.409 & 40 & 2.085 & \multirow{3}{*}{7.298} & \multirow{3}{*}{$0.00^{*}$} \\
\hline & \begin{tabular}{|l|} 
Within \\
\end{tabular} & 66.289 & 232 & \multirow{2}{*}{0.286} & & \\
\hline & Total & 149.698 & 272 & & & \\
\hline \multirow[t]{3}{*}{ Irresponsibility } & Between & 110.366 & 40 & 2.759 & \multirow{3}{*}{5.545} & \multirow{3}{*}{$0.00^{*}$} \\
\hline & \begin{tabular}{|l|} 
Within \\
\end{tabular} & 115.434 & 232 & \multirow{2}{*}{0.498} & & \\
\hline & Total & 225.800 & 272 & & & \\
\hline \multirow[t]{3}{*}{ Non-immediacy } & Between & 118.008 & 40 & 2.950 & \multirow{3}{*}{6.916} & \multirow{3}{*}{$0.00^{*}$} \\
\hline & \begin{tabular}{|l|} 
Within \\
\end{tabular} & 98.965 & 232 & \multirow{2}{*}{0.427} & & \\
\hline & Total & 216.973 & 272 & & & \\
\hline
\end{tabular}

\section{Discussion}

According to studies by Kearney et al(1991), Thweatt \& McCroskey, (1998) and Banfield et al (2006), student reported learning levels and perception of instructor credibility were definitely affected by teacher misbehavior.

The primary aim of the present study was to assess student perceptions of college teacher misbehavior and teacher credibility, while also aiming to investigate the relationship between teacher misbehavior and teacher credibility among a sample of students at the Hashemite University. The sample comprised 273 students who were required to respond to a teacher misbehavior scale and teacher credibility scale. The overall mean of student perception of teacher misbehavior and teacher credibility were rated medium level. Results also showed that irresponsibility was significantly and negatively associated with teacher credibility, while no significant correlations were found between derisiveness, incompetence and non-immediacy types of teacher misbehavior and teacher credibility.

Thweatt \& McCroskey (1998), identified three types of teacher displaying misbehavior dimensions, all of which had a strong negative impact on perceived teacher credibility.

A study by Banfield et al (2006) illustrated that perceived instructor credibility was inversely related to teacher misbehavior and negatively affected student evaluation of the instructor. Millette \& Gorham (2002) and Thweatt \& McCroskey (1998) found some evidence however that the impact of instructor misbehavior could be reduced by improved instructor immediacy levels.

Allen, Witt, \& Wheeless (2006) stating their findings that student motivation to learn and a consequent increase in student cognitive mastery of course content were positively affected by high immediacy levels.

In his study, Fassinger (1995) reiterates that previous research studies have established that student reactions and learning levels are compromised by student perception of misbehavior by the instructor, such as abuse of power in the classroom and other forms of inappropriate behavior. In addition to the aforementioned negative reactions to perceived teacher misbehavior, student interest and class participation are also diminished, students' class participation being defined as the comments or questions offered or raised by students in class

Junn (1994) terms student participation as an indispensable facet of an active learning process, while Petress (2006), states that students who participate in class interaction remember course content better than non-participants.

These findings are supported by a number of studies including those by

Christie \& Schuster (2003); Daly, Kreiser, \& Roghaar (1994); Reinsch \& Wambsganss (1994), and Voelkl (1995) who found that higher levels of student participation were reflected in higher exam scores and cumulative course grade averages.

Daly et al (1994) and Fassinger $(1995,2000)$ found that student participation is stimulated or diminished by teaching behavior, with student participation increased when the instructor is perceived as being approachable, responsive, and supportive, thereby encouraging student feedback.

Auster \& MacRone, (1994); Menzel \& Carrell (1999) and Myers et al, (2005), identify a number of positive attributes associated with student participation including: timely verbal response, being relaxed, attentive, open and friendly; making the class more interesting by being animated, dramatic, and leaving an impression; adopting a specific style of communicating rhetoric such as authoritative, contentious, precise, or dominant.

West \& Pearson (1994) add that active student participation and question asking in the classroom are elicited by those instructors who disclose personal opinions and pose questions.

Fassinger (1995b, 2000), posits a comprehensive summation, that student participation is promoted by teachers who communicate in an approachable and supportive manner.

Therefore, given the perception of misbehaving teachers as unapproachable and unsupportive, we may suspect student perceptions of teacher misbehavior to be direct predictors of student participation in class. 
The researcher comments that worthwhile future research could be undertaken in the following fields: to investigate the effect of teacher misbehavior on student communication behavior using new observation techniques; measuring actual recall as an outcome variable rather than relying on student self-reports in attempting to determine the effect of teacher misbehavior on actual memory, given the possibility that students' overall learning competencies rather than actual memory and recall capabilities are affected by teacher misbehavior.

\section{Limitations of the Study}

As is the case with all research projects this present study is not without limitations, the primary confine being its reliance on the self-report method of data collection. This method may result in a subjective negative assessment of teacher behavior by a student who has received a bad grade, is disinterested in or dislikes the subject matter. The influence of such factors on student appraisal of the teacher is known as the halo effect. The researcher's suggestion of observational data of instructor misbehavior in the classroom would therefore endorse or invalidate student perceptions, although this method was unfortunately not an option in data collection for the present study. A further consideration for future research could be investigation of instructor misbehavior in online instructor/student communication.

The second limitation was in asking research participants for their reactions to a hypothetical situation rather than one they had personally experienced, which may significantly influence participant response. The researcher therefore recommends using experimental observation in future research into the effects of teacher misbehavior on student communication, as well as evaluating actual recall as an outcome variable in determining whether actual memory is affected by teacher misbehavior, as opposed to the possibility that student effectiveness rather than actual recall is affected by teacher misbehavior. Further, findings of this study cannot be generalized on any other student population whether inside or outside Hashemite University students. Similarity, the findings are applicable to community of the study only the time of the study. Finally, the findings of this study could not be applicable to graduate students since there are excluded from the study.

\section{References}

Allen, M., Witt, P. L., \& Wheeless, L. (2006). The role of teacher immediacy as a motivational factor in student learning: Using metaanalysis to test a causal model. Communication Education, 55, 21-31.

Auster, C. J. \& MacRone, M. (1994). The classroom as a negotiated social setting: An empirical study of the effects of faculty members' behavior on students' participation. Teaching Sociology,22,289-300

Banfield, S. R., Richmond, V. P., \& McCroskey, J. C. (2006). The effect of teacher misbehaviors on teacher credibility and affect for the teacher. Communication Education, 55, 63-72.

Berkos, K. M., Allen, T. H., Kearney, P., \& Plax, T. G. (2001). When norms are violated: Imagined interactions as processing and coping mechanisms. Communication Monographs, 68, 289-300.

Christle, C. A., \& Schuster, J. W. (2003). The effects of using response cards on student participation, academic achievement, and on-task behavior during whole-class math instruction. Journal of Behavioral Education, 12(3), 147-165.

Christophel, D. M., \& Gorham, J. (1995).A test-retest analysis of student motivation, teacher immediacy, and perceived sources of motivation and demonization in college classes. Communication Education, 44, 292_306.

Daly, J. A., Kreiser, P. O., \& Roghaar, L. A. (1994). Question-asking comfort: Explorations of the demography of communication in the eighth grade classroom. Communication Education,43, 27-41.

Dolin, D. J. (1995).A in'tmisbehavin': A study of teacher misbehaviors, related communication behaviors, and student resistance. Unpublished doctoral dissertation, Morgantown: West Virginia University.

Fassinger, P.A. (1995a). Professors' and students' perceptions of why students participate in class. Teaching Sociology, 24, 25-33.

Fassinger, P. A. (1995b). Understanding classroom interaction: Students' and professors' contributions to students' silence. Journal of HigherEducation,66, 82-96.

Fassinger, P. A. (2000). How classes influence students' participation in college classrooms. Journal of Classroom Interaction, 35, 3847.

Gorham, J., \& Christophel, D. M. (1992).Students' perceptions of teacher behaviors as motivating and demotivating factors in college classes. Communication Quarterly, 40, 239_252.

Gorham, J., \& Millette, D. M. (1997).A comparative analysis of teacher and student perceptions of sources of motivation and demonization in college classes. Communication Education, 46,245-261.

Hattie, J. (2009). Visible learning: A synthesis of over 800 meta-analyses relating to achievement. New York, NY: Routledge.

Hsu, L. (2013). Development and Validation of a Questionnaire to Assess Taiwanese Teacher Misbehavior in the Classroom. Taipei, Taiwan: Bookman Books, Ltd.

Johnson, S. D., \& Miller, A. N. (2002).A cross-cultural study of immediacy, credibility, and learning in the U.S. and Kenya. Communication Education, 51, 280-292. 
Junn, E. (1994). Pearls of wisdom: Enhancing student class participation with an innovative exercise. Journal of Instructional Psychology , 21, 385-387.

Kearney, P., Plax, T. G., \& Allen, T. H. (2002). Understanding student reactions to teachers whom is behave. In J. L. Chesebro \& J. C. McCroskey (Eds.), Communication for teachers(pp. 127-140). Boston, MA: Allyn \& Bacon.

Kearney, P., Plax, T. G., Hays, E. R., \& Ivey, M. J. (1991). College teacher misbehaviors: What students don't like about what teachers say or do. Communication Quarterly, 39, 309-324.

Kearney, P., Plax, T. G., Sorensen, G., \& Smith, V. R. (1988).Experienced and prospective teachers 'elections of compliance-gaining messages for "common" student misbehaviors. Communication Education, 37, 150-164.

Kelsey, D. M., Kearney, P., Plax, T. G., Allen, T. H., \& Ritter, K. J. (2004).College students' attributions of teacher misbehaviors. Communication Education, 53, 40-55.

Lewis, R., \& Riley, P. (2009).Teacher misbehavior. In L. J. Saha \& A.

G. Dworkin (Eds.), The new international handbook of teachers and teaching(pp. 417-431). Norwell, MA: Springer.

McCroskey, J. C., Holdridge, W., \& Toomb, J. K. (1974).An instrument for measuring the source credibility of basic speech communication instructors. Speech Teacher, 33, 26-33.

McCroskey, J. C., \& Young, T. J. (1981). Ethos and credibility: The construct and its measurement after three decades. Central States Speech Journal, 32, 24-34.

McMillan, J.J., \& Cheney, G. (1996). The student as consumer: The implications and limitations of a metaphor. Communication Education, 45, 1-15.

McPherson, M. B., Kearney, P., \& Plax, T. G. (2006).College teacher misbehaviors. In T. P. Mottet,V. P. Richmond, \& J. C. McCroskey (Eds.), Handbook of instructional communication: Rhetorical and relational perspectives (pp. 213_234). Boston: Allyn\& Bacon.

McPherson, M. B., \& Young, S. L. (2004). What students think when teachers get upset: Fundamental attribution error and studentgenerated reasons for teacher anger. Communication Quarterly, 52, 357_369.

Menzel, K. E. \& Carrell, L. J. (1999).The impact of gender and immediacy on willingness to talk and perceived learning. Communication Education, 48, 31-40.

Millette, D. M., \& Gorham, J. (2002).Teacher behavior and student motivation. In J. L. Cheseboro \& J. C. McCroskey (Eds.), Communication for teachers(pp. 141-153). Boston, MA: Allyn \& Bacon.

Myers, S. A. (2002). Perceived aggressive instructor communication and student state motivation, learning, and satisfaction. Communication Reports, 15, 113-121.

Myers, S.A. , \& Martin, M. M. (2006). Understanding the source: Teacher credibility and aggressive communication traits. In T. P. Mottet, ed. , V. P. Richmond,, ed. \& J. C. McCroskey (Eds.), Handbook of instructional communication: Rhetorical and relational perspectives (pp. 67-88). Boston: Allyn \& Bacon.

Myers, S. A., Rocca, K. A., Dunleavy, K. N., Hanselman, M., Ike, I., Kubic, K.(2005, April).The relationship between college student class participation and perceived instructor communicator style. Pittsburgh, PA: Paper presented at the annual meeting of the Eastern Communication Association.

Petress, K. (2006).An Operational Definition of Classroom Participation. College Student Journal, 40, 821-823.

Pozo-Munoz, C., Rebolloso-Pacheco, E., \& Fernandez-Ramirez, B. (2000). The "ideal teacher:"Implications for student evaluation of teacher effectiveness. Assessment and Evaluation in Higher Education, 25, 253-264.

Reinsch, R. \& Wambsganss, J. R. (1994). Class participation: How it affects results on examinations. Journal of Education for Business, 70, 33-37.

Russ, T. L., Simonds, C. J., \& Hunt, S. K. (2002). Coming out in the classroom...An occupational hazard? The influence of sexual orientation on teacher credibility and perceived student learning. Communication Education, 51(3), 311-324.

Schrodt, P. (2003). Students' appraisals of instructors as a function of students' perceptions of instructors' aggressive communication. Communication Education, 52, 106_121.

Teven, J. J., \& McCroskey, J. C. (1997).The relationship of perceived teacher caring with student learning and teacher evaluation. Communication Education, 46, 1-9.

Thweatt, K. S. \& McCroskey, J. C. (1996). Teacher non-immediacy and misbehavior: Unintentional negative communication. Communication Research Reports, 13, 198-204.

Thweatt, K. S., \&McCroskey, J. C. (1998).The impact of teacher immediacy and misbehaviors on teacher credibility. Communication Education, 47, 348-358.

Toale, M. C. (2001). Teacher clarity and teacher misbehaviors: Relationships with students' affective learning and teacher credibility. Unpublished doctoral dissertation, Morgantown: West Virginia University.

Voelkl, K. E. (1995). School warmth, student participation, and achievement. Journal of Experimental Education,63, 127-138

Wanzer, M. B., \& McCroskey, J. C. (1998). Teacher socio-communicative style as a correlate of student affect toward teacher and course material. Communication Education , 47, 43-52.

West, R. \& Pearson, J. C. (1994). Antecedent and consequent conditions of student questioning: An analysis of classroom discourse across the university. Communication Education, 43, 299-311.

Zhang, Q. (2007). Teacher misbehaviors as learning demotivators in college classrooms: A cross cultural investigation in China, Germany, Japan, and the United States. Communication Education, 56, 209-227. 